\title{
Social Dominance Orientation and John Henryism at the Intersection of Race and Class
}

\author{
Melissa R. Sanders \\ University of Michigan \\ Ramaswami Mahalingam \\ University of Michigan
}

\begin{abstract}
Three studies were conducted to explore the relationship between social dominance orientation (SDO) and John Henryism (JH). Each study was framed using an intersectionality perspective which predicted that specific combinations of social identities would impact endorsement of SDO and JH in unique ways. We hypothesized that upper-class non-Whites would be higher in SDO and lower in JH than any other class/race identity combination. As predicted, a Class $\times$ Race interaction emerged for both SDO and JH in Study $1(\mathrm{~N}=387)$, with upper-class non-Whites displaying the highest levels of SDO and the lowest levels of JH. Study $2(\mathrm{~N}=340)$ replicated these findings and also explored the impact of context-level class on SDO and JH. Using a qualitative method, in Study $3(\mathrm{~N}=23)$ we found that upper-class non-Whites described their social class positions in ways highly consistent with SDO, whereas middle/working-class non-Whites described their experiences in ways consistent with JH.
\end{abstract}

KEY WORDS: social dominance orientation, John Henryism, intersectionality

Social location plays a critical role in how we view and interpret the social structures that shape various aspects of our lives. Sociologists like Bourdieu (1977) theorized the notion of habitus, where there is a correspondence between a social position and personal disposition which shapes the implicit beliefs that are embedded in our social practices and discourses. Social psychologists interested in delineating the relationship between power and psychological disposition have focused on how privileged social locations shape beliefs about social hierarchies (Jost \& Banaji, 1994; Mahalingam, 2007; Pratto et al., 2000). The converging evidence from these studies indicates that those who are in positions of privilege tend to view social hierarchies as a natural part of our social world, as measured by social dominance orientation (SDO), and tend to have a lower awareness of various privileges. SDO, however, gives us little insight into how those in marginalized social locations cope with the naturalization of existing social hierarchies. Research on John Henryism (JH) has examined how marginalized group members, such as African Americans, cope with discrimination. This line of research has demonstrated that specific interactions between race and class play a critical role in moderating the beneficial effects of $\mathrm{JH}$ on physical health. So far, no studies have looked at the relationship between JH and SDO, two of the dominant constructs in the psychological research on privilege and social marginality.

Using an intersectionality framework (Cole, 2009; Stewart \& McDermott, 2004), we investigated the relationship between SDO and $\mathrm{JH}$. We adopted an intersectionality framework to 
explore how demographic social identities interact to shape the endorsement of these ways of thinking. Specifically, the studies presented here focus on three main issues: first, how SDO and $\mathrm{JH}$ relate to one another; second, whether intersections of specific social identities impact the endorsement of these constructs in unique ways which would not be accounted for by looking at those identities separately; and third, whether individuals describe their social location in ways that converged with findings on SDO and JH. Study 1 and Study 2 were quantitative survey-based designs, and Study 3 was a qualitative analysis of narrative accounts of class identity in an intergroup context.

\section{Theoretical Perspectives}

\section{Social Dominance Orientation}

Social dominance theory was originally conceptualized and developed as a framework to understand how social hierarchies are formed and maintained and has been a vibrant line of research for over two decades (Levin, 2004; Levin, Federico, Sidanius, \& Rabinowitz, 2002; Pratto, Sidanius, \& Levin, 2006). Social dominance orientation (SDO) can be described as a general orientation or outlook that shapes how an individual understands social hierarchies. It has been found to be stable across time and situations and functions like a dispositional personality variable (Pratto et al., 2006). It correlates strongly with political conservatism and modern racism (Jost \& Thompson, 2000; Miller, Smith, \& Mackie, 2004; Pratto et al., 2006).

Pratto et al. (2006) argue that those in privileged positions develop a stronger SDO in order to preserve their privileged position. Members of dominant groups are more likely to endorse ideologies which legitimize and support inequalities that favor them. A long body of research finds that men and Whites tend to score higher on measures of SDO than women and ethnic/racial minorities. SDO also predicts privileged group members' political orientation and their attitudes toward race, and their attitudes toward immigration policies (Miller et al., 2004; Pratto et al., 2006). SDO has been one of the most robust cognitive measures of privileged group members' political views and attitudes toward marginalized group members. However, studies of SDO with marginalized group members tend to have lower reliability, possibly because this particular worldview does not reflect their lived experience (Pratto et al., 2006). In addition, research on SDO does not fully explore the interaction between social class and race or how class itself shapes attitudes towards social hierarchies.

\section{John Henryism}

John Henryism (JH), or the dispositional tendency to employ high-effort coping strategies when faced with persistent structural obstacles, focuses on the experience of marginalized group members. James (1994) developed a theory of active coping specific to the Black community using the American folk tale of John Henry as a touchstone of racially shared experience. This famous story focused on the attempts of a Black railroad worker to prove his skill (and by extension keep his job) against the threat of mechanization. In the end, John Henry wins the race against the machine, proving his skill and his effectiveness, but at the cost of his life. John Henry, though victorious, drives himself too far too quickly and dies moments after the close of the race. James saw this story as the crystallization of a coping strategy employed by Blacks in response to overt racism and structural discrimination. James argued that in the face of these chronic life stressors, Blacks adopt a higheffort coping strategy (termed John Henryism) where they locate their success or failure in their ability to work hard enough to overcome obstacles.

In keeping with James' initial framing of the concept, much of the research on JH has been conducted in the realm of health psychology. James (1994) presented the John Henryism Hypothesis, 
which argued that a high-effort coping strategy like JH would increase physiological reactivity, which would in turn lead to higher health risks. Active coping strategies like this one, which require an individual to invest a large amount of emotional, behavioral, and cognitive effort and resources, may have a particularly vicious backlash if they are not successful. Although such a focus on self-efficacy and self-reliance can be quite positive if one is successful, he found that those who aren't - those whose conditions never changed no matter how hard they worked-suffered health complications as a result. Low-income Blacks high in JH have been found to have dangerously high blood pressure and are at a high risk for heart disease. Similarly, Duijkers, Drijver, Krumhout, and James (1988) found that Dutch men high in JH also had high blood pressure.

There is also evidence that in some circumstances, high levels of $\mathrm{JH}$ can be beneficial. When the active coping strategy succeeds, it can become a protective factor against those same health risks it seems to exacerbate-high SES Blacks high in JH have been shown to have lower blood pressure (Bennett et al., 2004). Dutch people in smoking cessation courses high in JH were found to be more successful in their attempts to stop smoking than those low in JH (Van Loon, Tijhuis, Surtees, \& Ormel, 2001), suggesting that adopting this strategy can galvanize one mentally for undertaking a long-term and difficult problem. Haritatos, Mahalingam, and James (2007) also found that higher SES Chinese immigrants high in JH had lower perceived stress and better health outcomes. Higher levels of JH have also been found to facilitate more perseverance and achievement among women in engineering school, graduate students of color, and lower-income students in higher education (Cheng et al., 2008; Darling, Molina, Sanders, Lee, \& Zhao, 2008). The emerging body of research on $\mathrm{JH}$ underscores the importance of the interaction between race and class.

Although John Henryism ( $\mathrm{JH})$ is conceptualized as a coping strategy and SDO is seen as a general orientation toward privilege which shape our worldview, we argue that they may be conceptually related. Both, for example, are focused on responses to inequality and social hierarchies. $\mathrm{JH}$ is essentially one way of coping with the knowledge that inequality exists, while SDO focuses on whether we think such an inequality is appropriate and natural. Like SDO, there is evidence that JH is a dispositional variable. Twin studies show that $35 \%$ of the variability of $\mathrm{JH}$ may be related to genetic factors (Bennett et al., 2004). Thus, we argue that in many ways JH and SDO can be seen as two sides of the same coin.

It is important to realize that, as psychological constructs, JH and SDO are oppositional. As mentioned, SDO is an orientation that best describes and reflects the outlook of those benefitting from the current structural hierarchies, while $\mathrm{JH}$ is a way for those who do not benefit from structural inequalities to deal with that fact. Therefore, JH can be considered a more resistance-based ideology, one that seeks system change (albeit on a small scale and at the individual level), than SDO.

In order to understand why we argue that JH and SDO represent oppositional ideologies, we need to differentiate JH from the Protestant Work Ethic (PWE). On the surface, PWE and JH seem highly similar: PWE describes the importance an individual places on hard work. PWE is described as having the following components: centrality of work, avoidance of wasting time, delay of gratification, morality/ethics, hard work leads to desirable outcomes, and self-reliance (Christopher, Zabel, Jones, \& Marek, 2008). Previous research has shown that PWE is related broadly to conservative ideologies, as is SDO (Christopher et al., 2008). There is support for the idea that PWE is positively related to SDO as well (Christopher \& Mull, 2006).

The general qualities of JH - efficacious mental and physical vigor, strong commitment to hard work, and single-minded determination to succeed-appear to overlap with at least the last two components of PWE (Bennett et al., 2004). However, we argue that in fact JH and PWE are separate constructs and may not interact with SDO the same way. While PWE requires some belief in a just world or fair play, essentially arguing that the link between hard work and success is clear and stable (Christopher et al., 2008), JH does not make this assumption. Instead, JH acknowledges the obstacles faced by marginalized groups and suggests hard work is a way to challenge and possibly overcome 
the unequal "starting places" of different groups. As such, some have argued that JH represents an ideology that emphasizes perseverance, persistence, and resistance to existing social structures through hard work (Haritatos et al., 2007). Given that challenge and critique of current structural inequalities is embedded in this construct, we suggest that it is not convergent with PWE.

\section{Intersectionality}

Social identities, such as race, are ever-present and important elements of the long lines of research for both SDO and JH. SDO, as described above, posits explanations for ubiquitous social phenomena such as racism and sexual double standards. JH was originally conceptualized specifically to investigate the negative health effects that disproportionately plague racial and ethnic minorities. However, very little research has investigated whether the intersections of these social identities affect JH and SDO in unique ways.

Intersectionality theory argues that individuals' beliefs, self-concepts, and behaviors must be understood as a product of the intersection of sociopsychological processes related to race, gender, and class (Mahalingam \& Leu, 2005). As such, the individual's gender, class, and ethnic identity are omnirelevant and always present. Because these social experiences are so intertwined and entangled, the intersectionality perspective argues for a nonadditive understanding of identity: a working-class Latina understands her educational experiences as a working-class Latina, not simply as a Latina who is working-class or as a working-class woman who happens to be Latina (Yoder \& Aniakudo, 1997). Intersectionality researchers also argue that we need to use mixed methods to study how intersecting identities simultaneously affect our lives. Combining quantitative and qualitative methods will help us explore how social context shapes our perceptions of privilege and social hierarchies.

The interrelationships between multiple social identities are at the heart of intersectionality, and there is evidence that social class as a subjective identity interacts with other identities in different ways. Much of the qualitative work on social class has focused on the lived experience of class. Differences have been found in the values and expectations held by members of different classes (Bettie, 2003), but it has also been pointed out that the members within a particular class negotiate values and expectations differently as well (Fine, Weis, Addelston, \& Marusza, 1997).

In sum, we argue that SDO and JH represent two different perspectives adopted by those living in a class-based hierarchical society. SDO focuses on ideological beliefs that justify existing power hierarchies whereas JH captures the spirit of resilience and coping of those who are at the marginalized locations. SDO measures legitimizing beliefs that naturalize existing social hierarchies, whereas JH captures the agency and resilience of those who resist such naturalization of social hierarchies. These two belief systems typify how dominant and marginalized group members' respond to issues related to power and marginalization. Therefore, we expect that those who are high on JH will be low on SDO.

Based on the findings from the research on $\mathrm{JH}$, we know that race and class interact in a dynamic way to predict Blacks' health outcomes. We employ an intersectionality framework to explore this finding in greater depth and extend it to cognitive factors like SDO. We are particularly interested in how the possible intersections between race and class play out in the context of higher education. Stewart and Ostrove (1993) have argued that higher education is a site of classbased socialization, one that strives to prepare economically advantaged students to adopt and function in the roles those of their status are expected to take on in the future. For upper-class non-Whites, their privileged class identity may serve as a buffer when they enter higher education. They may find that due to their class identity their transition is much easier than it is for middle/ working-class students. Their class identity, unlike their racial or ethnic identity, is congruous with the goals and values of the institution they find themselves in (Bourdieu, 1977). As a protective 
measure, it makes sense that they would adhere to this identity as closely as they could and endorse a perhaps exaggerated version of the worldview endorsed by upper-class Whites. In sum, we expect that upper-class non-Whites will face a similar predicament and will endorse ideologies that legitimize the social hierarchies they benefit from. That is, they will score high on SDO and low on $\mathrm{JH}$.

In contrast, based on previous research regarding race and class, we would not expect middle/ working-class Whites to show the same pattern despite their comparative race-based privilege. Weis (2003) found that working-class gender ideologies emerge through a process of sexist and racist "othering" used by White working-class men to differentiate themselves from women and people of color. Women are seen as vulnerable, domestic, and dependent, leading working-class men to construct masculinity in terms of the ability to hold down a job, to be the primary or sole economic provider for the household, and also to protect White women from racial and ethnic minority men. Additionally, the categorization of mental labor as feminine leads White working-class men to become academically disengaged and seek occupations that emphasize physical strength or manual dexterity (Argyle, 1994). In essence, these men are emphasizing their maleness and Whiteness for the same reason that we suggest upper-class non-Whites would emphasize their class identity: doing so enables them to fashion an identity which highlights the ways they best fit with their context and downplays the ways in which they don't. Thus, an intersectionality perspective enables us to look at the interaction between social class and race in novel ways.

\section{The Current Research}

We conducted three studies to explore the relationship between SDO and JH and the ways these psychological constructs are shaped by social location. We employed both quantitative and qualitative methods to investigate the following hypotheses:

Hypothesis 1: SDO and JH will be negatively correlated with each other.

Hypothesis 2: In addition to replicating the main effects of class, race, and gender previously established in the literature, we predict that intersecting identities will have multiplicative (not additive) effects on the endorsement of SDO and JH. Specifically, we predict that upper-class non-Whites will score higher on SDO and lower on JH than any other group.

Hypothesis 3: Analyses of intergroup dialogue class papers will show that non-White upper-class students tacitly accept the hierarchies (i.e., their class status) that privilege them. By contrast, non-White working-class students will emphasize hard work as a means to overcome social marginalization. They will also challenge the status quo and be more critical of social hierarchies.

\section{Study 1}

In Study 1, we explored the relationship between SDO and JH using a quantitative survey methodology. We also investigated how various demographic social identities (race, class, and gender) impacted and shaped individuals' endorsement of JH and SDO.

\section{Methods}

Participants. A total of 387 undergraduates from a large Midwestern university in the United States participated in this study. Participants were drawn from the psychology subject pool and 
were given course credit for their participation. The sample was composed of 181 men, 202 women, and 4 participants who chose not to disclose their gender. The sample was predominantly White (277 participants), but also contained 45 Asian-Americans, 15 Blacks, 13 Latino/as, 24 individuals who identified as "other," 11 multiracial individuals, and 2 participants who chose not to provide an answer.

Participants generally came from solidly upper middle-class families with highly educated mothers, both indicators of relatively high socioeconomic status. Reported annual family income is as follows: 37 reported less than $\$ 50,000$; 45 reported $\$ 50,000-\$ 75,000$; 65 reported $\$ 75,000$ $\$ 100,000 ; 84$ reported $\$ 100.000-\$ 150,000 ; 53$ reported $\$ 150,000-\$ 200,000$; and 82 reported more than $\$ 200,000$. Of the sample, 21 participants did not answer this question. In terms of mother's highest level of education, 47 participants reported a high school degree or less, 45 had mothers who had completed some college, 33 had mothers with an Associate's degree, 143 had mothers with a Bachelor's degree, and 119 had mothers with a postgraduate degree.

\section{Materials}

Social dominance orientation. Participants completed Sidanius and Pratto's (2001) social dominance orientation (SDO) scale, a 16-item scale that measures an individual's tendency to see inequality and social hierarchies as natural and acceptable ("It is okay if some groups have more of a chance in life than others"; "Some groups of people are simply inferior to other groups."). Participants rated the items using a 7-point Likert scale where 1 was strongly disagree and 7 was strongly agree. This scale was found to be reliable $(\alpha=.82)$, and higher scores suggest a more socially dominant outlook.

John Henryism. Participants also completed James' (1994) John Henryism (JH) scale, a 12-item scale which measures active coping in response to long-term stressors ("I've always felt that I could make my life pretty much what I wanted it to make of it"; "When things don't go the way I want them to, that just makes me work even harder."). Participants rated how well the items reflected their lives using a 5-point Likert scale where 1 was completely false and 5 was completely true. This scale was highly reliable $(\alpha=.93)$, and higher scores suggested stronger endorsement of John Henryism.

Procedure. Participants signed up for the study using the subject pool's online system. Once they signed up, participants were emailed a link to a web survey. After completing the consent form, participants completed a measure of SDO, a measure of $\mathrm{JH}$, and a set of demographic questions (gender, age, race, annual family income, and subjective class identification). Subjective class identification was measured by asking the participant to identify with one of the following socioeconomic class labels: working-class, lower middle-class, middle-class, upper middle-class, and upper-class. They were then presented with a debrief form and given course credit.

\section{Results}

\section{Preliminary Considerations}

To determine how best to operationalize social class, one of our primary variables of interest, we ran bivariate correlations between reported annual family income, mother's highest level of education, and subjective class identification. Table 1 shows that all three measures of social class were highly correlated. We chose to conduct the following analyses on subjective class because we felt it best reflects the participants' psychological experience of their social class status. Additionally, since the number of participants for any category other than White was too small to allow for meaningful 
Table 1. Correlations Between Class Measures in Study 1

\begin{tabular}{lccc}
\hline & Mother's Education & Income & Subjective Class \\
\hline Mother's education & - & $.38^{*}$ & $.33^{*}$ \\
Income & & - & $.75^{*}$ \\
\hline
\end{tabular}

*indicates significance at the $p<.001$ level.

Table 2. Multiple Regression on SDO in Study 1

\begin{tabular}{lccccc}
\hline & $\mathrm{B}$ & $(\mathrm{SE}) \mathrm{B}$ & $\beta$ & $\mathrm{t}$ & $\mathrm{p}$ \\
\hline Race & .24 & .19 & .11 & 2.30 & .02 \\
Class & .19 & .05 & .20 & 4.18 & $<.001$ \\
Gender & -.49 & .09 & -.26 & -5.41 & $<.001$ \\
Race $\times$ Class & .23 & .10 & .11 & 2.23 & .03 \\
\hline
\end{tabular}

analysis, we created a binary categorical variable for race, which resulted in 277 White participants and 110 non-White participants. ${ }^{1}$

Main analyses. As predicted, JH and SDO were found to be negatively correlated with one another, $r(387)=-.24, p<.001$. Multiple regressions were used to explore the effects of class, race, and gender on the endorsement of SDO and JH. The regressions were conducted separately for SDO and $\mathrm{JH}$ using centered gender, binary race, and class as predictors. All possible interaction terms were created for the analyses using the centered predictors and entered as predictors.

A regression on SDO was statistically significant, $R^{2}=.13, p<.001$. Table 2 shows that gender, race, and class all emerged as significant predictors. Gender and class both related to SDO in the expected directions: men and those from higher socioeconomic backgrounds were more likely to strongly endorse SDO. However, non-Whites were found to endorse SDO more strongly than Whites. This unexpected finding is qualified by the hypothesized Race $\times$ Class interaction, which was found to be significant. As Figure 1 shows, White participants tended to have stable levels of SDO across class categories. For non-Whites, in contrast, upper-class and upper middle-class non-White showed higher levels of SDO than any other groups.

The regression on $\mathrm{JH}$ was also statistically significant, $R^{2}=.04, p=.004$. Table 3 shows that race and gender emerged as significant predictors of $\mathrm{JH}$, but class did not. Women were found to have significantly higher $\mathrm{JH}$ than men. Again, race did not predict JH in the expected direction-nonWhites reported lower levels of JH than Whites-but this was qualified by a significant Race $\times$ Class interaction. Figure 2 shows essentially an inverse of Figure 1. Specifically, upper middle-class and upper-class non-White participants showed lower levels of JH than all other groups.

\section{Discussion}

As predicted, we found that SDO and $\mathrm{JH}$ are negatively correlated (Hypothesis 1). We also found that social location does influence the degree to which SDO or JH is adopted. Those coming from privileged backgrounds (men and upper-class participants) tended to be higher in SDO and lower in $\mathrm{JH}$ than those coming from marginalized positions (women and middle/working-class

\footnotetext{
${ }^{1}$ In Study 1, an initial ANOVA was conducted on SDO and JH with race entered as a fixed factor. To test whether there were differences between minority racial/ethnic groups, we included only non-White participants in this analysis. We found no significant main effects or interactions on the ANOVA conducted in this manner for either SDO or JH. An initial set of ANOVAs on SDO and JH with race and class entered as fixed factors were conducted on any participants identifying themselves as anything other than White in Study 2, as well. Again, we found no significant main effects or interactions on the ANOVA conducted in this manner for either SDO or JH.
} 


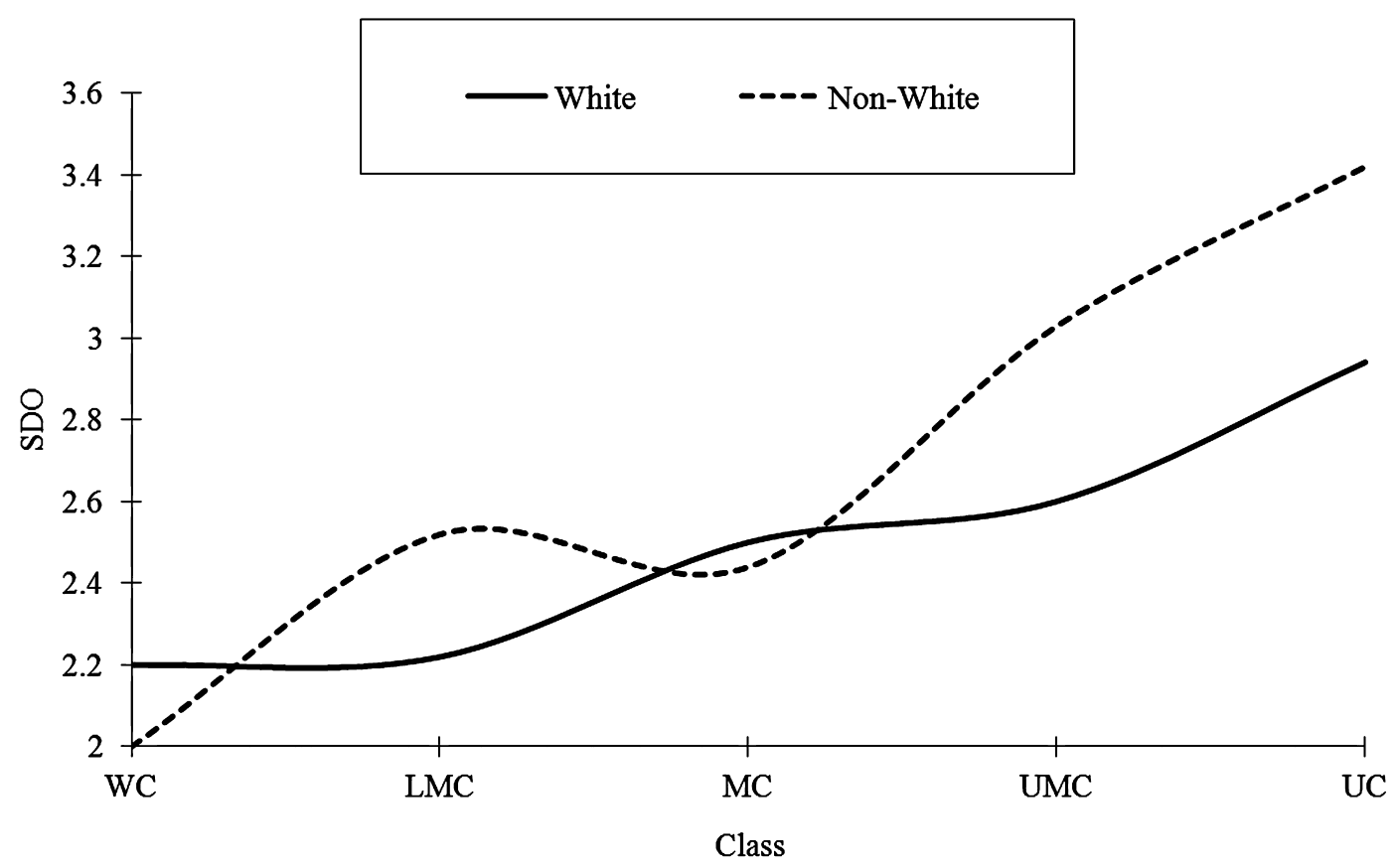

Figure 1. Class $\times$ Race interaction on SDO in Study 1 .

Table 3. Multiple Regression on JH in Study 1

\begin{tabular}{lccccc}
\hline & $\mathrm{B}$ & $(\mathrm{SE}) \mathrm{B}$ & $\beta$ & $t$ & $p$ \\
\hline Race & -.10 & .06 & -.09 & -1.75 & .08 \\
Class & -.03 & .03 & -.05 & -1.00 & .32 \\
Gender & .14 & .05 & .14 & 2.83 & .005 \\
Race $\times$ Class & -.12 & .06 & -.11 & -2.16 & .03 \\
\hline
\end{tabular}

participants). For both variables, the hypothesized Class $\times$ Race interaction emerged, and our analysis revealed that upper-class non-White participants were highest in SDO and lowest in JH compared to the other groups. These findings provide support to Hypothesis 2, that the endorsement of these differing ideologies are influenced in unique and nuanced ways by the intersections of particular social identities.

\section{Study 2}

In Study 2, we replicated our findings from Study 1. We also wanted to broaden the scope of our approach and take into account not only the influence of an individual's subjective class identification, but also the broader social class of the individual's context. A number of researchers have noted that working-class college students and first-generation college students, those who lack the social capital to easily negotiate such institutions, grapple with issues of "fit" (Bergerson, 2007; Jones, 2003). Class differences that had been previously hidden may become quite clear when working-class students realize that they do not necessarily hold the same expectations and worldviews as their classmates. The combination of additional pressures and burgeoning class awareness makes the transition to college for high-achieving low-income students a rocky one. 


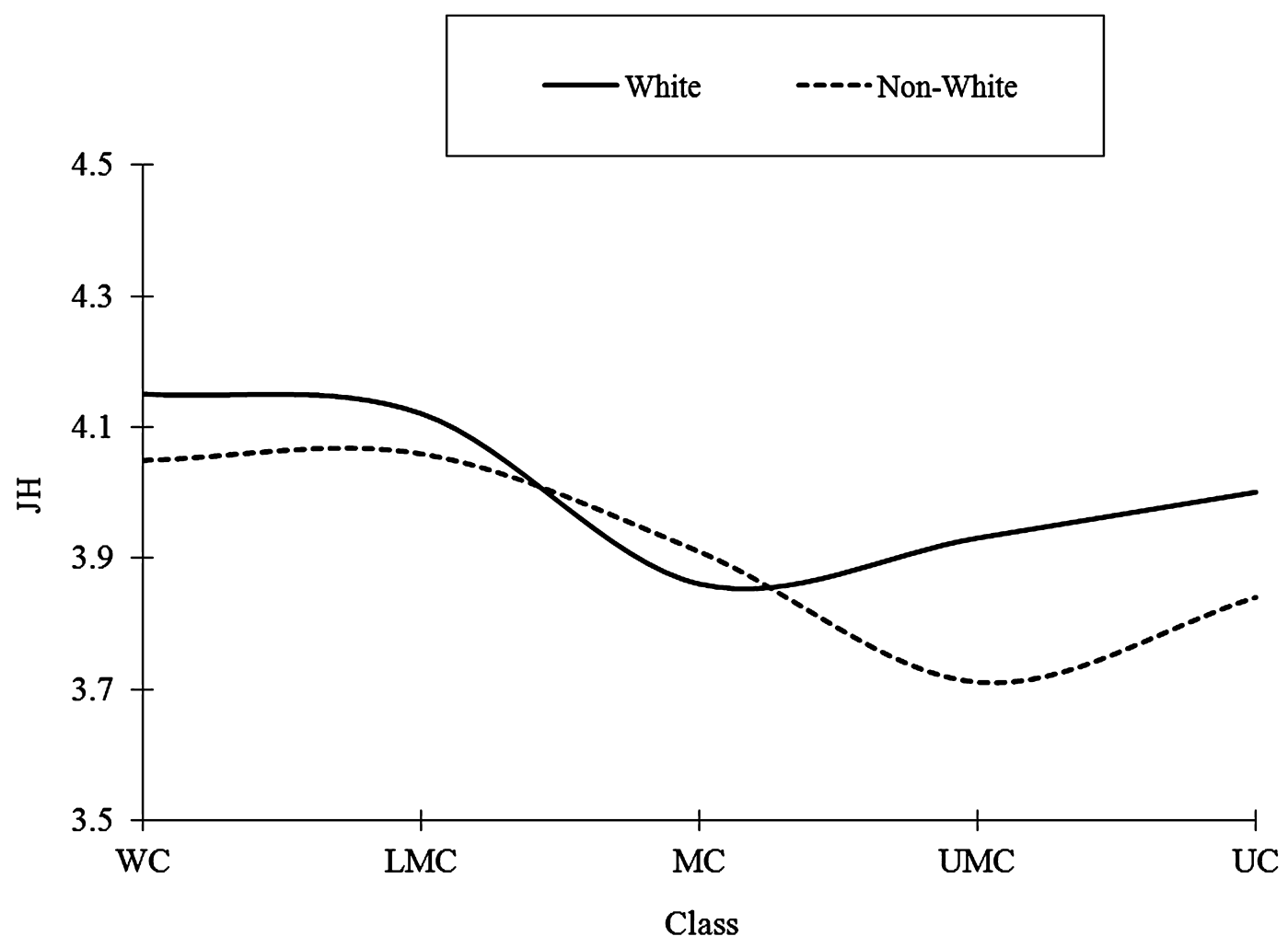

Figure 2. Class $\times$ Race interaction on $\mathrm{JH}$ in Study 1 .

Certain institutions of higher learning, however, cater specifically to lower-income students. It was unclear to us, given the results of Study 1 which was conducted at an institution of higher education which may elicit such issues of "fit," if this is consigned to higher education generally or might be associated with certain types of institutions within higher education. To this end, we decided to investigate how students in a community college endorsed SDO and JH. We were specifically interested in how context-level class and individual-level class might interact, but given that this research is largely exploratory, we did not formulate formal hypotheses about how such interactions might play out. We did, however, expect to replicate out findings from Study 1: JH and SDO would be negatively correlated and non-White upper middle and upper-class individuals would have the highest rates of SDO and the lowest rates of JH.

One sample was collected at the authors' home institution in Midwestern USA, using the same psychology subject pool used in Study 1. Income and subjective class data from Study 1 established that students at this high-ranking, highly selective university tend to be White and wealthy. The median income was over $\$ 200,000$, and the majority of students identified as upper middle-class or upper-class. Data collected for this study converges with our previous findings. Seventy-three percent of participants reported an annual family income of over $\$ 100,000$, and $56 \%$ identified themselves as upper middle-class or upper-class. Additionally, $87 \%$ of participants' mothers held a Bachelor's degree or higher.

The second sample was collected at a small community college located in a working-class town of approximately 30,000 people located about 20 miles east of Houston, Texas, USA. We collected the same indicators of social class at this research site: mother's highest level of education, annual 
family income, and subjectively identified class status. Of this sample, $24 \%$ of participants reported an annual family income of over $\$ 100,000$. No participants identified as upper-class, and only $29 \%$ identified as upper middle-class. $60 \%$ of participants' mothers held a Bachelor's degree or higher. Compared to our home institution, this community college in East Texas serves a population that is generally less educated and less economically advantaged.

\section{Methods}

Participants. A total of 263 undergraduates from a large Midwestern university in the United States participated in this study. The composition of the sample was balanced in terms of gender (108 men, 151 women, 4 chose not to answer) but not in terms of race (195 Whites, 9 African Americans, 30 Asian-Americans, 6 Latino/Hispanics, 22 “other," 2 multiracial individuals, and 4 individuals who chose not to answer). Participants' ages ranged from 17 to 27 years old. As in Study 1, participants were drawn from the psychology subject pool and given course credit for participation.

Additionally, 77 students from a community college in East Texas, USA participated in this study. This sample included 31 men and 46 women. Of the sample, 45 students identified as White, 6 as African American, 3 as Asian-American, 19 as Latino/Hispanic, and 4 as "other." Ages for this sample ranged from 16 to 47 years old. These participants completed a paper and pencil version of the survey in psychology classes at the community college. They were given no compensation for their participation.

Materials and procedures. The materials and procedures used for the Midwestern sample were identical to those used in Study 1. Materials were modified to accommodate administering paper-andpencil versions of the survey for the East Texas sample and references to compensation were removed from the consent form. All participants completed the SDO measure $(\alpha=.93$ for the Midwestern sample and $\alpha=.70$ for the East Texas sample ${ }^{2}$ ), the JH measure ( $\alpha=.77$ for the Midwestern sample and $\alpha=.70$ for the East Texas sample), and the demographics questionnaire used in Study 1.

\section{Results}

Once again, we ran bivariate correlations between our measures of class. All were significantly positively correlated (see Table 4). As in Study 1, we used subjective class identification as our indicator of class in the analyses reported below. A binary categorical variable was created for race using the same procedures used in Study 1.

Bivariate correlations revealed that SDO and $\mathrm{JH}$ were negatively correlated, $r(340)=-.20$, $p<.001$. Multiple regressions were used to explore the effects of class, race, and gender on the endorsement of SDO and JH. The regressions were conducted separately for SDO and JH using centered research site, gender, binary race, and class as predictors. All possible interaction terms were created for the analyses using the centered predictors and included as predictors.

Table 4. Correlations Between Class Measures in Study 2

\begin{tabular}{lccc}
\hline & Mother's Education & Income & \multicolumn{2}{c}{ Subjective Class } \\
\hline Mother's education & - & $.29^{*}$ & $.26^{*}$ \\
Income & - & - & $.60^{*}$ \\
\hline
\end{tabular}

*indicates significance at the $p<.001$ level.

\footnotetext{
${ }^{2}$ Given Pratto, Sidanius, and Levin's (2006) finding that traditionally marginalized groups tend to show lower rates of internal consistency on the SDO scale than privileged groups, this difference in reliability is to be expected.
} 
Table 5. Multiple Regression on SDO in Study 2

\begin{tabular}{lccccc}
\hline & B & (SE)B & $\beta$ & $t$ & $p$ \\
\hline Race & .24 & .12 & .11 & 1.99 & .05 \\
Class & .43 & .11 & .21 & 3.96 & $<.001$ \\
Gender & -.55 & .11 & -.27 & -5.19 & $<.001$ \\
Research Site & -.20 & .14 & -.08 & -1.50 & .14 \\
Race $\times$ Class & .53 & .24 & .12 & 2.20 & .03 \\
Research Site $\times$ Class & .60 & .27 & .12 & 2.25 & .03 \\
\hline
\end{tabular}

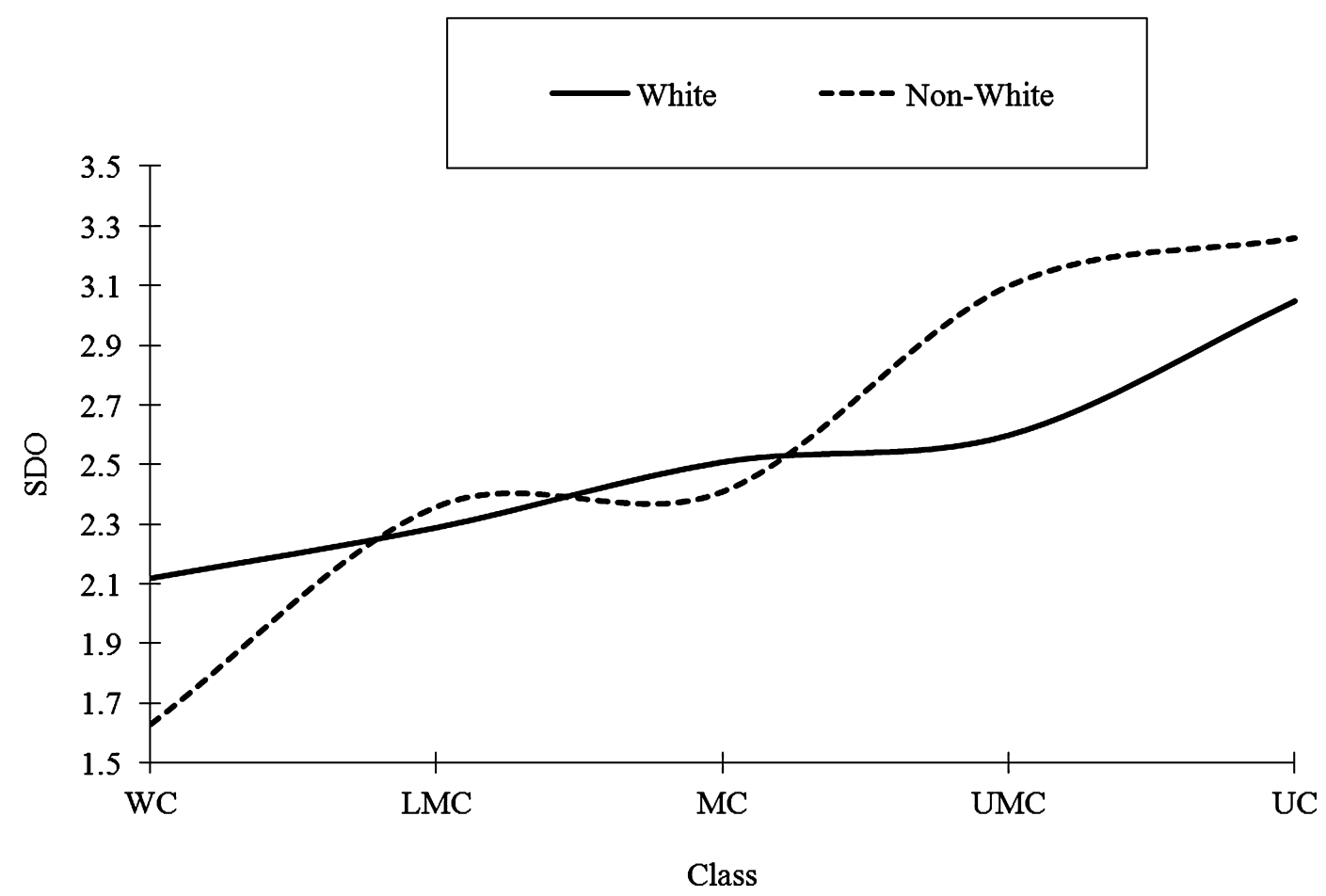

Figure 3. Race $\times$ Class interaction on SDO in Study 2 .

A regression on SDO was statistically significant, $R^{2}=.15, p<.001$. Table 5 shows that gender, race, and class all emerged as significant predictors. Gender and class both related to SDO in the expected directions: men and those from higher socioeconomic backgrounds were more likely to strongly endorse SDO. However, non-Whites were found to endorse SDO more strongly than Whites. This unexpected finding is qualified by the hypothesized Race $\times$ Class interaction, which was found to be significant. As Figure 3 shows, White participants tended to have stable levels of SDO across class categories. For non-Whites, in contrast, upper-class and upper middle-class non-White showed higher levels of SDO than any other groups. Additionally, we found a significant Research Site $\times$ Class interaction. As Figure 4 shows, the East Texan participants show no class differences on JH. The working-class, lower middle-class, and middle-class Midwestern participants, on the other hand, had lower levels of SDO than other groups.

The regression on $\mathrm{JH}$ was also statistically significant, $R^{2}=.08, p<.001$. Table 6 shows that gender emerged as a significant predictor of $\mathrm{JH}$, but race, class, and research site did not. Women 


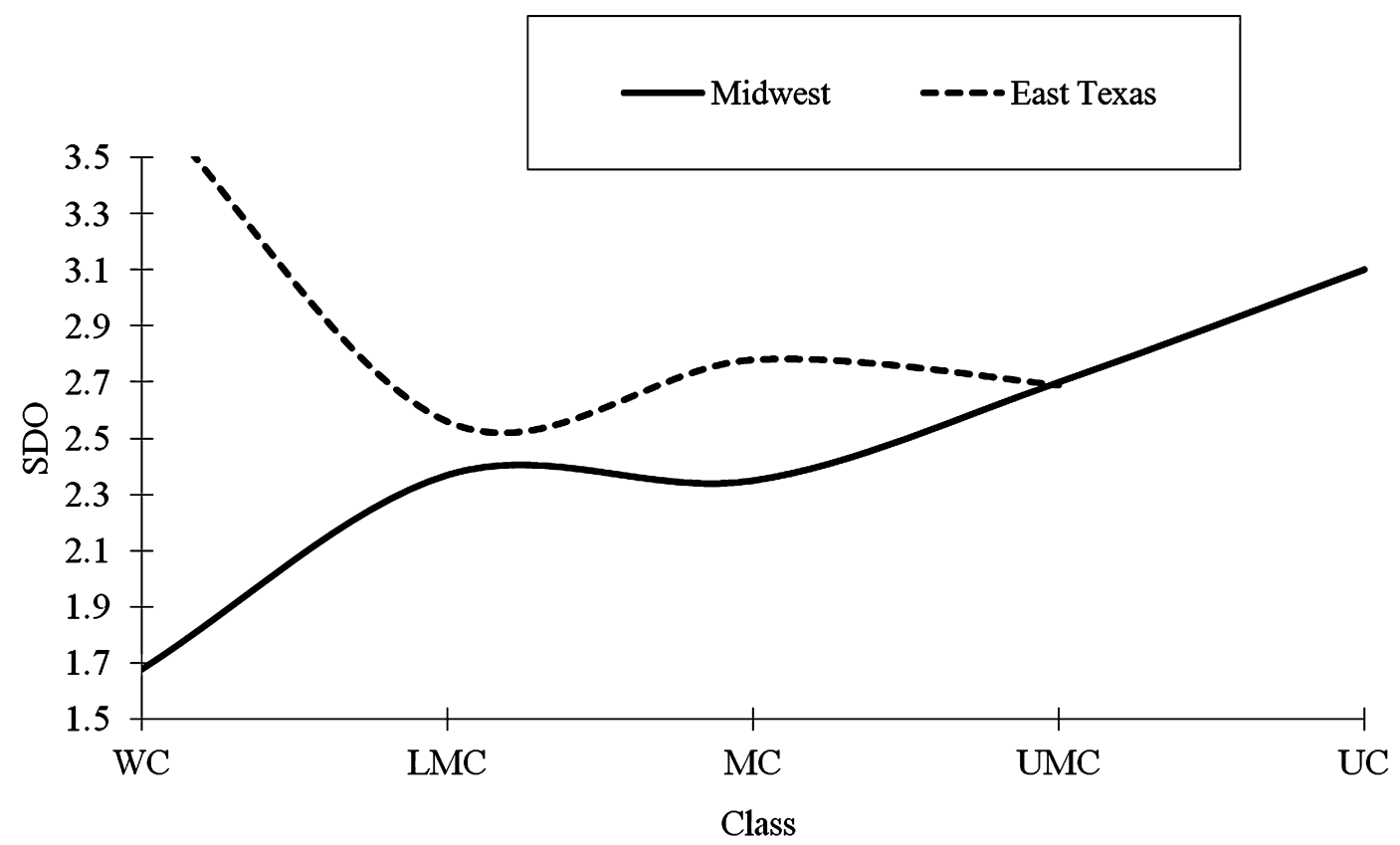

Figure 4. Class $\times$ Research Site interaction on SDO in Study 2 .

Table 6. Multiple Regression on JH in Study 2

\begin{tabular}{lccccc}
\hline & B & $($ SE)B & $\beta$ & $t$ & $p$ \\
\hline Race & -.02 & .06 & -.02 & -.33 & .74 \\
Class & -.04 & .05 & -.05 & -.80 & .42 \\
Gender & .16 & .05 & .16 & 3.06 & .002 \\
Research Site & -.10 & .07 & -.09 & -1.59 & .11 \\
Research Site $\times$ Race & -.34 & .13 & -.15 & -2.63 & .009 \\
\hline
\end{tabular}

were found to have significantly higher $\mathrm{JH}$ than men. The expected Race $\times$ Class interaction was not significant, but a significant Race $\times$ Research Site interaction did emerge. As Figure 5 shows, JH remained consistent across research sites for White participants. For non-White participants, however, non-Whites in East Texas had substantially higher rates of $\mathrm{JH}$ than non-Whites in the Midwest.

\section{Discussion}

The findings from Study 2 partially replicate and expand our findings from Study 1. Once again, we found that SDO and JH are negatively correlated (Hypothesis 1) and that social location leads to differential endorsement of these two worldviews. In Study 2, we also found the same pattern of Class $\times$ Race interactions that emerged in Study 1 for SDO, but not for JH. This suggests that our finding that upper-class non-Whites are typically high in SDO compared to other class/race groups is stable and is found across different contexts (Hypothesis 2).

The findings from Study 2 also showed that the class level of a participant's context does shape his/her endorsement of JH and SDO in ways that cannot be accounted for by his/her own individual 


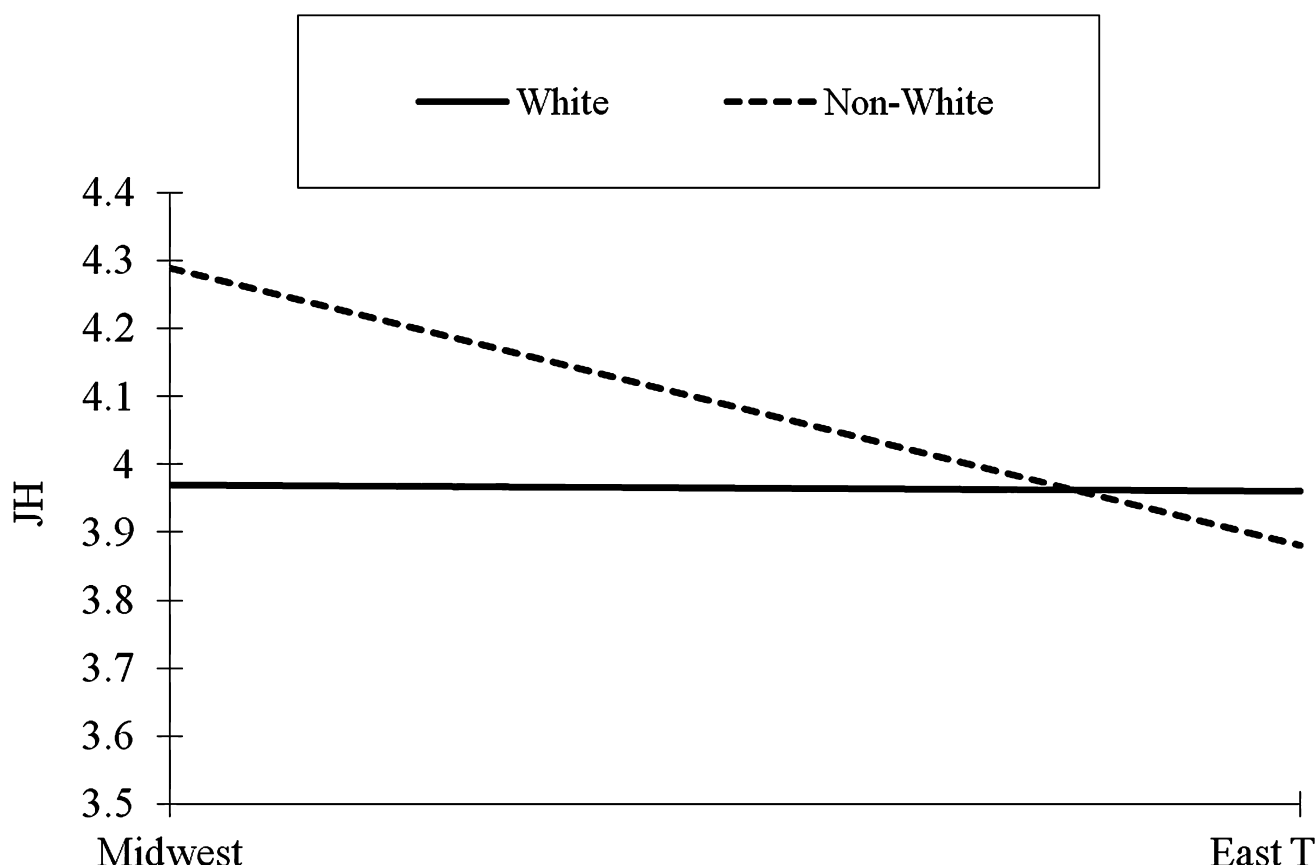

Midwest

East Texas

\section{Research Site}

Figure 5. Race $\times$ Research Site interaction on JH in Study 2 .

level of class alone. Interestingly, we found no main effect of research site for either SDO or JH. However, we found that the East Texan participants had levels of SDO that were similar to those of upper-class Midwesterners. Middle/working-class Midwesterners, or those students whose personal class level was lower than the class level of their broader educational context, showed lower levels of SDO than all other groups, suggesting a dynamic interplay between individual and context class levels. Additionally, we found that White participants' levels of JH seemed consistent across educational context whereas non-White participants in East Texas reported greater endorsement of JH than non-Whites in the Midwest.

In Studies 1 and 2, we did not measure the strength of class identity. As social identity theory researchers have found, levels of SDO are influenced in part by one's perceived ingroup status and strength of identification to that ingroup (Schmitt, Branscombe, \& Kappen, 2003). Thus, it is unclear in Studies 1 and 2 if the effect we predict and find-namely that upper-class non-Whites are higher in SDO and lower in JH than comparison groups-occurs because they find themselves in a context in which their class status is more salient than their racial or ethnic status.

We decided to explore the salience and strength of class identity in an intergroup context where social class was the focus of intergroup dialogue over a semester. There is evidence that institutes of higher education serve as class-based sites of socialization and have a highly classed culture (Bergerson, 2007; Bourdieu, 1977), and we propose that enrollment in a prestigious and selective university will highlight students' class status. Participation in a dialogue course at this prestigious, selective university should result in a context where social class is highly salient and apparent to students. We decided to use qualitative method to explore the salience of intergroup dialogue on class differences within a non-White sample. 


\section{Study 3}

In order to more fully understand why upper-class non-Whites adopt a cognitive framework that is highly consistent with SDO and not $\mathrm{JH}$, we conducted a qualitative study. We investigated how upper-class and middle/working-class non-White students in a semester-long intergroup dialogue course on socioeconomic status constructed and articulated their perceptions of hierarchy and social mobility. Based on the findings from Studies 1 and 2, we expected middle/workingclass students to cite hard work as the primary mechanism through which upward mobility can be achieved. We argue that such narrative accounts of selfhood illustrate the basic tenets of John Henryism (James, 1994). We also expected upper-class non-White students to take a more reductionist or naturalistic perspective of social hierarchy than middle/working-class non-White students.

Our findings from Studies 1 and 2 showed that the most extreme differences in endorsement of JH and SDO occurred between non-White participants. Since it was this difference between the non-Whites that seemed to be driving the interaction, we focused only on upper and middle/workingclass non-White participants in this study.

\section{Method}

Participants. Archival analysis was conducted on a set of 23 final papers from students who were enrolled in a semester-long intergroup dialogue process specifically focusing on social class. Students self-selected into the intergroup program, but were not able to choose the focus of their dialogue course. Thus, the students included here range from those excited by a dialogue course about social class to those who began the course uninterested in these issues. The final paper required students to reflect on what they had learned about social class in general and what they had discovered about their own social class identity throughout the course. As such, these papers provided a unique opportunity to get an in-depth look at how individuals process social class from multiple angles and in great detail.

In order to protect participants' anonymity, the researchers did not have access to any identifying or demographic information about the students. All demographic information, therefore, had to be disclosed within the paper by the student themselves. We limited our analysis for this project to those students who self-identified both their race or ethnicity as anything other than White and provided information about their socioeconomic status. The final sample of papers included 16 middle/ working non-Whites and 7 upper-class non-Whites.

\section{Coding}

Thematic content analysis was conducted on this set of 23 papers. We created a coding scheme for this project using the following multistep process. First, the authors of this paper read a subset of 10 papers and identified possible themes of interest. We then discussed which themes to pursue and how to identify the presence of those themes in the text of subsequent papers. These initial 10 papers were excluded from any further analysis.

In the second step, the authors used this coding scheme to analyze all other papers which fit the criteria listed above: the students writing the paper had to disclose their class status and their race/ethnicity, and their race/ethnicity had to be described as something other than White. Multiracial individuals were included in our analysis. Each paper was coded for the presence or absence of relevant themes. We compared our codings and revised the developing coding scheme.

When the coding scheme was sufficiently clarified and revised, two blind coders were trained independently to use it. They analyzed all the papers in isolation from the authors and from each 
other. Once all coding had been completed, we compared the agreement of their codes with one another and with the first author. Both coders were highly reliable with each other (agreement in $96 \%$ of cases) and with the first author (agreement in 97\% of cases). This established the reliability of the coding scheme used in our analysis. The analysis reported below is drawn from the first author's codes.

\section{Results}

Theme 1-Explanations for social inequality. In many of the papers, students grappled with questions of inequality and hierarchies within society at length. Such discussions, we argue, are reflective of the same concepts underlying SDO (Pratto et al., 2006). We were particularly interested in class-based differences in how the existence of these social hierarchies were justified, resisted, and accounted for by non-White students.

Theme 1 among middle/working-class non-Whites. There were two kinds of responses from middle/working-class non-Whites in how they explained social inequality. Some highlighted the arbitrary nature of existing social hierarchies. Some highlighted the social constructionist nature of social class.

We found that middle/working-class students tended to highlight the arbitrary nature of the existing hierarchies and used their belief that such hierarchies are inherently social constructions as a basis to undermine their legitimacy.

We have this desire, people in general, to create a structure-a hierarchy. If there was no hierarchy, we would search for one. When these different groups immigrated to the United States, they were inferior for some reason-some reason people needed to create. This is similar to the case with Blacks. The color of their skin was one thing different, hence another way to make others feel superiority. I think our society is constantly in search of this "one thing" to make others feel inferior-whatever that may be. As a result, we have constructed a social hierarchy that we "need." (Participant 119; middle/working-class Black woman)

The above quote illustrates the middle/working-class non-White students' tendency to take a critical approach to hierarchy. They discussed the inherent human tendency to create hierarchies and differences while emphasizing that the axes upon which these differences were made are inherently arbitrary. In this sense, these students may tacitly agree with someone endorsing a high level of SDO that hierarchy is "natural." However, they do not accept that marginalized groups are marginalized on the basis of any sort of inherently meaningful criteria.

Another way middle/working-class non-Whites approached the existence of hierarchies and their subordinate position within them was by pointing out the socially constructed nature of dominant stereotypes about social class.

There are obstacles blocking the way for those of lower SES to succeed and rise above their status. For example, our culture creates a gap between the rich and the poor. Those who do not fit the mold of what the rich expect people to look like, act like, or work as are seen as inferior. (Participant 63; middle/working-class Latina)

Many of the wealthy students in my dialogue never consciously tried to distinguish themselves as superior . . . society said they were superior. (Participant 44; middle/working-class Black woman) 
These quotes suggest that middle/working-class non-White students resist internalizing the dominant explanations for why low-SES individuals are low SES. They are not seeing their social class as reflective of their own abilities. Instead, they are interpreting their marginalized class status as an arbitrary social category along the lines of race or gender: a constructed social marker that is used to enforce hierarchical differences.

Theme 1 among upper-class non-Whites. Upper-class non-White students, in contrast, approached social hierarchies with a very different perspective. They viewed social hierarchy as a natural part of the social order. They also emphasized the unchanging nature of social hierarchies. Both these views reflect and at times mirror some of the items in the SDO scale ("It is okay if some groups have more of a chance in life than others"; "Some groups of people are simply inferior to other groups."). Specifically regarding their privileged class status, these students took a sort of "que sera sera" approach - that these differences exist and there is little they can do to mitigate them.

I am glad that the other group [the lower SES students] talked about how there is no reason to feel guilty for being in the "upper-class." As they said, there is no reason to feel guilty, and if anything, they shouldn't put us in a position where we have to feel guilty. (Participant 16 ; upper-class Indian man)

I have wondered for a long time how I can be an ally with the people in a lower economic status. There is little I can do to ally with them. It is basically a society problem rather than the problem of the attitude of people. (Participant 12; upper-class Asian man)

Unlike the middle/working-class non-Whites who sought to undermine the legitimacy of class-based hierarchies by emphasizing the arbitrary nature of these differences, the upper-class non-Whites regard a class-based hierarchy that privileges them with a passive acceptance. The first participant's quote above rejects feelings of class-based guilt (citing responses from his classmates which he interprets as an acquittal of his privileged position), which tacitly gives support to class-based hierarchy. The second quote takes this a step further. In contrast to the social constructivist position of his middle/working-class counterparts, this student locates the origins of hierarchy in the fundamental workings of society. He explicitly rejects class-based hierarchy as matter of individuals' perceptions or beliefs. By doing so, he naturalizes the existing pecking order.

Additionally, some upper-class non-Whites extended this perspective more broadly, couching discrimination and oppression as a dispositional rather than structural phenomenon.

There will always be racist, sexist and just people who are full of hatred in the world. (Participant 129; upper-class Black woman)

The idea that oppression is rooted in "bad eggs" may be a way for this student to explain away her own class-based privilege. Instead of acknowledging her own unearned privileges and questioning whether she has engaged in classist behavior, she sidesteps these concerns by reframing the issues as one of personality instead of context. Furthermore, she takes a particularly fatalistic approach to the problem. Implicit in her quote is the idea that if there are always bad eggs, there is no real way to combat discrimination and oppression.

Theme 2-The role of hard work. The second prominent theme that emerged was related to the role of hard work and social mobility. Conceptually, both of these ideas are clearly linked to JH. We found that almost all of the middle/working-class non-Whites discussed the role of hard work or expressed some hope of upward mobility in the future. This theme was virtually absent among upper-class non-Whites. 
Theme 2 among middle/working-class non-Whites. Many middle/working-class non-Whites were quite explicit in their endorsement of hard work and their feelings of self-efficacy.

I ultimately believe I can do anything I put my mind to. (Participant 58; middle/workingclass Black woman)

I learned that if a person works hard they can achieve much more than their SES says they can achieve. A person doesn't have to remain in their status, either. (Participant 26; middle/working-class Black woman)

The quotes above show a clear belief in the power of hard work. The first quote, for instance, is extremely close to the wording of several items from the JH scale (i.e., "Hard work has really helped me to get ahead in life.") used in Studies 1 and 2 (which was not presented to these students). Additionally, middle/working-class students discussed hard work in terms of their prospects for upward mobility in the future.

I know that one day I will be rich and comfortable if I continue to work as hard as I have been. I have learned that higher SES are just people and because they have unearned wealth does not mean that they are any better than I am, it just means I have to work a bit harder to get where I want to be. (Participant 62; middle/working-class Black man)

I am part of the working-class. It isn't my fault, it is unearned. I don't blame my mother, my mom raised me, therefore until I get to working full time I will consider myself part of her socioeconomic class. (Participant 119; middle/working-class Black woman)

These two students have a clear sense of their own social class status, and their papers suggest a level of dissatisfaction with it. Both of them point out that the factor they believe gained them admission to a prestigious university - hard work-will be the same one that eventually elevates them to the next rung in the class ladder. This high level of self-efficacy and self-reliance is also found in populations high in $\mathrm{JH}$.

A number of the middle/working-class non-Whites took a more nuanced view of hard work and their social identities. While these students, like the ones above, saw hard work as their biggest strength and the best mechanism they had to move up to a different social class, they also recognized that their intersecting identities led to more obstacles they needed to overcome to reach those goals.

I remember my dad always used to tell me, "Son, as a minority, you have to work twice as hard as others to get the equal treatment and recognition." I truly believe every word of that. (Participant 85; middle/working-class Chinese man)

I know that I can determine where I end up but not where I began. Being a black person with a low socio-economic level or working-class level is like a double negative. To be black sends so many messages. You are forced to prove yourself in so many ways and make sure that you are up to par and on top of everything. (Participant 62; middle/working-class Black man)

I know after this course that me being an African American woman and me being of a lower socioeconomic status have something to do with one another. They have a negative effect on one another and with the stereotypes that accompany them I have to work harder to defeat them in order to succeed. (Participant 56; middle/working-class Black woman) 
These students recognize the structural factors in place in regard to their marginalized position as women, lower-income people, and people of color, but still see upward social mobility as a possible (perhaps even likely) future outcome. They acknowledge that they will have to work harder than those in positions of privilege, but all seem to suggest that they are capable of meeting the challenge posed by their intersecting marginalized identities.

Theme 2 among upper-class non-Whites. While hard work was rarely mentioned in this group, when it was it had a distinctly different character than when it was discussed by their middle/ working-class counterparts. When they did talk about hard work, they did not present it as necessary to overcome obstacles.

Another slight thing that bothers me is all the hoopla surrounding affirmative action. When I applied to [this] university, affirmative action was still happening. [My] university only gave additional points for admission for minorities who were African American, Latino, or Native American. Hence, affirmative action did not apply at all for me [as a South Asian]. I received no additional points for being a minority. However, my fellow classmates did not know this. They assumed that since I was a minority my chances for admission were automatically increased. I had to work just as hard as Whites did to get admission into Michigan. (Participant 16; upper-class Indian man)

There are two things of interest embedded in the quote above. First, in contrast to the middle/workingclass non-Whites who describe themselves as having to work harder than White students, this student describes himself as working just as hard as White students. Thus, he implicitly places himself at the same level with students privileged in terms of their race, with the same (lack of) obstacles. He is not discussing the role of his ethnic or class identity in shaping his opportunities for learning. Second, though this student is a minority himself, he holds a negative view of Affirmative Action policies, which suggests that his class-based privileges may have shielded him from a number of the issues facing middle/working-class non-Whites when they apply to college.

\section{Discussion}

We found strong support for both our predictions. As expected, upper-class non-Whites accepted existing class-based social hierarchies as natural and not particularly problematic and were less likely to emphasize the role of hard work in their successes than middle/working-class non-Whites. These findings provide much-needed insight into our quantitative results from Studies 1 and 2.

These findings add qualitative support to the findings from the previous studies where NonWhite upper-class students were the highest on SDO and lowest on JH. This follows Hurtado's (1989) argument that individuals with membership in both dominant and subordinate groups will tend to cling to the privileged aspects of their identity more than the marginalized aspects of their identity if their surrounding context allows it. Hurtado (1989) also suggests that those who are marginalized in multiple ways will be more resistant to legitimizing myths. The middle/workingclass Non-White students in this study discussed social structures and mobility in ways that captured the spirit of the John Henryism measure. These students displayed a high level of agentic coping and resistance to the naturalization of their marginalized positions.

These findings also raise some interesting questions for future research. We did not have access to students' immigration status or the immigration status of their parents. It is possible, given that within our sample race tended to separate out across class lines (Asian-Americans tended to be higher class while Blacks and Latino students tended to identify as working/middle-class), that the 
more economically advantaged students may be first- or second-generation immigrants coming to higher education from a different socioeconomic context.

Despite our inability to untangle these questions of race, class, and immigration status, we believe findings from this study provide an interesting insight into why our participants may have responded the way they did to the JH and SDO scales in Study 1 and Study 2. While the sample is small and limited, the qualitative data provided here nonetheless provides us with a view of how issues of stratification are internalized and understood along class lines. Furthermore, this study shows that the way individuals spontaneously discuss their position in society mirrors the language in the JH and SDO scales.

\section{General Discussion}

We found support for all of our hypotheses. In both Studies 1 and 2 we found that SDO and JH were negatively correlated with one another. This relationship emerged in both a high-SES and low-SES context. While this finding holds a great deal of intuitive purchase, this is the first time it has been demonstrated (Hypothesis 1). Class $\times$ Race interactions emerged for both JH and SDO in Study 1 and Study 2, as well. In both studies, upper-class non-Whites displayed the highest levels of SDO. In Study 1, we also found that non-White upper-class participants had the lowest levels of JH (Hypothesis 2). In Study 3, a qualitative study looking at students' narrative expressions of their social identities, we found that participants generated themes that coincided with SDO and JH. As predicted, the narratives of upper-class non-Whites reflected a greater degree of acceptance of social hierarchy and little regard for the importance of hard work (Hypothesis 3), which closely mirrors our quantitative findings.

These findings emphasize the interactive effect social class and race has on how we interpret and approach our own marginalized identities. It should be noted that these interactive effects are shaped by the context, as well. We found that class at the context level interacted with participants' individual level of class to predict SDO. Specifically, we found that individuals who had a lower individual class than the broader context (middle/working-class students in the Midwest) tended to be less likely than others to endorse SDO. We also found that non-White students in East Texas, the lower SES research site, most strongly endorsed JH, a resistant, system-challenging ideology. Finally, it should be noted that we found no main effect of research site on either JH or SDO; that is, it was not that the participants in the lower SES context were generally lower on SDO and higher on JH overall. Context-level effects emerged as interactions. Taken together, these findings emphasize that the contexts in which we conduct social science research impact our findings in nuanced ways. Researchers need to be cognizant of such interactive effects between the individual and the context. Future research is needed to explore how this phenomenon plays out in other contexts with other social identities.

\section{Limitations and Future Directions}

The research presented here clearly does not explore every dimension of social identity which is relevant to ideology or the context of higher education. Gender, for example, was not a main focus of our research but is an interesting axis upon which questions of ideology can be asked. We found in both Study 1 and Study 2 that women tended to be higher on JH and lower on SDO than men, but we found no intersections to qualify these main effects as we did for our other two social identities of interest (race and class). This certainly does not mean women of color and White women understand and construct their worldview the same way or that affluent and economically struggling women react the same way to unequal societal structures. What is needed to tease these things apart is for future researchers to carefully construct research questions that provide insight into these issues. 
As noted above, this research focused on social identities within the context of higher education. This research, then, tells us little about how such identities are managed by young adults not pursuing higher education, a group that tends to be understudied. There is some research to suggest that identity may be expressed or form differently among working-class young adults not enrolled in college. Morash (1980) compared the identity-status frequencies of a group of working-class young adult men who had already entered the workplace with previously published middle-class samples and found that the working-class participants underwent different identity-formation processes than their middle-class college-bound counterparts. Going back to Weis's (2003) research on workingclass White men's disengagement from mental labor, it certainly seems that young adults who choose not to pursue higher education construct their identities differently than those who do pursue higher education. As it stands, the ways in which their differently constructed identities shape their endorsement of various ideological positions remains an open question. Future research on social class should take care to include both student and nonstudent populations.

Finally, one of the major limitations of Study 3, the lack of known immigrant status of the participants, raises a number of possible avenues for future research. First, it highlights the problem of collapsing across all non-White races and ethnicities, which rendered us unable to tease out how the model minority myth, for example, might relate to SDO or JH among Asian Americans. Second, it shows that race as a social category is itself nested within other social categories. When possible, such social categories should be teased apart to better understand the downstream effects they have. Locating issues of race and class in a transnational perspective, which forces us to rethink how such identities are constructed, is becoming more and more a pressing issue in today's world.

\section{Conclusion}

Using an intersectionality framework, we demonstrated that specific combinations of social identities have very different effects on participants' differential endorsement of SDO and JH. Although previous research has found that non-Whites in general tend to be low in SDO and high in $\mathrm{JH}$, a more nuanced approach showed that upper-class non-Whites reacted to these constructs very differently than middle/working-class non-Whites. Upper-class non-Whites were found to be higher in SDO and lower in JH than any other group, in some sense endorsing an exaggerated version of the pattern found among the most privileged group, upper-class Whites. We argue that this finding has to be understood with the context of an economically advantaged higher education setting.

\section{ACKNOWLEDGMENTS}

Correspondence concerning this article should be sent to Melissa R. Sanders, Department of Psychology, University of Michigan, Ann Arbor, MI 48105. Email: mrsander@umich.edu

\section{REFERENCES}

Argyle, M. (1994). The psychology of social class. New York: Routledge.

Bennett, G. G., Merritt, M. M., Edwards, C. L., Whitfield, K. E., Brandon, D. T., \& Tucker, R. D. (2004). Stress, coping, and health outcomes among African-Americans: A review of the John Henryism Hypothesis. Psychology \& Health, 19, 369-383.

Bergerson, A. A. (2007). Exploring the impact of social class on adjustment to college: Anna's story. International Journal of Qualitative Studies in Education, 20, 99-119.

Bettie, J. (2003). Women without class: Girls, race, and identity. Berkeley: University of California Press.

Bourdieu, P. (1977). Outline of a theory of practice. Cambridge: Cambridge University Press.

Cheng, C., Sanders, M. R., Sanchez-Burks, J., Molina, K., Lee, F., Darling, E., \& Zhao, Y. (2008). Reaping the rewards of diversity: The role of identity integration. Social and Personality Psychology Compass, 2, 1182-1198. 
Cole, E. R. (2009). Intersectionality and research in psychology. American Psychologist, 64, 170-180.

Christopher, A. N., \& Mull, M. S. (2006). Conservative ideology and ambivalent sexism. Psychology of Women Quarterly, 30 , 223-230.

Christopher, A. N., Zabel, K. L., Jones, J. R., \& Marek, P. (2008). Protestant ethic ideology: Its multifaceted relationships with just world beliefs, social dominance orientation, and right-wing authoritarianism. Personality and Individual Differences, 45, 473-477.

Darling, E., Molina, K., Sanders, M. R., Lee, F., \& Zhao, Y. (2008). Belonging and achieving: The role of identity integration. In M. Maehr, S. Karabenick, \& T. Urdan (Eds.) Advances in motivation and achievement: Social psychological perspective on motivation and achievement (Vol. 15, pp. 241-273). New York: Elsevier.

Duijkers, T. J., Drijver, M., Kromhout, D., \& James, S. A. (1988). "John Henryism” and blood pressure in a Dutch population. Psychosomatic Medicine, 50, 353-359.

Fine, M., Weis, L., Addelston, J., \& Marusza, J. (1997). (In)secure times: Constructing white working-class masculinities in the late 20th century. Gender and Society, 11, 52-68.

Haritatos, J., Mahalingam, R., \& James, S. A. (2007). John Henryism, self-reported physical health indicators, and the mediating role of perceived stress among high socio-economic status Asian immigrants. Social Sciences \& Medicine, 64, 1192-1203.

Hurtado, A. (1989). Relating to privilege: Seduction and rejection in the subordination of White women and women of Color. Signs, 14, 833-855.

James, S. A. (1994). John Henryism and the health of African-Americans. Culture, Medicine and Psychiatry, 18, $163-182$.

Jones, S. J. (2003). Complex subjectivities: Class, ethnicity, and race in women's narratives of upward mobility. Journal of Social Issues, 59, 803-820.

Jost, J. T., \& Banaji, M. R. (1994). The role stereotyping in system justification and the production of false consciousness. British Journal of Social Psychology, 33, 1-27.

Jost, J. T., \& Thompson, E. P. (2000). Group-based dominance and opposition to equality as independent predictors of self-esteem, ethnocentrism, and social policy attitudes among African Americans and European Americans. Journal of Experimental Social Psychology, 36, 209-232.

Levin, S. (2004). Group status differences and the effects of gender, ethnicity, and religion on social dominance orientation. Political Psychology, 25, 31-48.

Levin, S., Federico, C. M., Sidanius, J., \& Rabinowitz, J. L. (2002). Social dominance orientation and intergroup bias: The legitimation of favoritism for high-status groups. Personality and Social Psychology Bulletin, 28, 144-157.

Mahalingam, R. (2007). Essentialism, power, and the representation of social categories: A folk sociology perspective. Human Development, 50, 300-319.

Mahalingam, R., \& Leu, J. (2005). Culture, essentialism, immigration and representations of gender. Theory \& Psychology, 15, 839-860.

Miller, D. A., Smith, E. R., \& Mackie, D. M. (2004). Effects of intergroup contact and political predispositions on prejudice: Role of intergroup emotions. Group Processes \& Intergroup Relations, 7, $221-237$.

Morash, M. (1980). Working-class membership and the adolescent identity crisis. Adolescence, 15, 313-320.

Pratto, F., Liu, J. H., Levin, S., Sidanius, J., Shih, M., Bachrach, H., \& Hegarty, P. (2000). Social dominance orientation and the legitimization of inequality across cultures. Journal of Cross-Cultural Psychology, 31, 369-409.

Pratto, F., Sidanius, J., \& Levin, S. (2006). Social dominance theory and the dynamics of intergroup relations: Taking stock and looking forward. European Review of Social Psychology, 17, 271-320.

Schmitt, M. T., Branscombe, N. R., \& Kappen, D. M. (2003). Attitudes toward group-based inequality: Social dominance or social identity? British Journal of Social Psychology, 42, 161-186.

Sidanius, J., \& Pratto, F. (2001). Social dominance: An intergroup theory of social hierarchy and oppression. Cambridge: Cambridge University Press.

Stewart, A. J., \& McDermott, C. (2004). Gender in psychology. Annual Review of Psychology, 55, 519-544.

Stewart, A. J., \& Ostrove, J. M. (1993). Social class, social change, and gender: Working-class women at Radcliffe and after. Psychology of Women Quarterly, 17, 475-497.

Van Loon, J. M., Tijhuis, M., Surtees, P. G., \& Ormel, J. (2001). Personality and coping: Their relationship with lifestyle risk factors for cancer. Personality and Individual Differences, 31, 541-555.

Weis, L. (2003). Acquiring White working-class identities: Legitimate and silenced discourse within the school. In M. Fine \& L. Weis (Eds.), Silenced voices and extraordinary conversations: Re-imagining schools (pp. 88-108). New York: Teachers College Press.

Yoder, J. D., \& Aniakudo, P. (1997). "Outsider within" the firehouse: Subordination and difference in the social interactions of African American women firefighters. Gender \& Society, 11, 324-341. 